\title{
Free-space and underwater GHz data transmission using AIGaInN laser diode technology
}

\author{
S.P. Najda ${ }^{1}$, P. Perlin ${ }^{1,2}$, T. Suski ${ }^{2}$, L. Marona ${ }^{2}$, M. Boćkowski ${ }^{1,2}$, M. Leszczyński ${ }^{1,2}$, \\ P. Wisniewski ${ }^{1,2}$, R. Czernecki ${ }^{1,2}$, R. Kucharski ${ }^{3}$, G. Targowski ${ }^{1}$, S. Watson ${ }^{4}$, and A.E.Kelly ${ }^{4}$.
}

1) TopGaN Ltd., ul. Sokolowska 29/37, 01-142 Warsaw, Poland.

2) Institute of High Pressure Physics PAS, ul. Sokolowska 29/37, 01-142 Warsaw, Poland.

3) Ammono S.A., Czerwonego Krzyz a 2/31, 00-377 Warsaw, Poland.

4) School of Engineering, University of Glasgow, Glasgow G12 8LT, U.K

\begin{abstract}
Laser diodes fabricated from the AlGaInN material system is an emerging technology for defence and security applications; in particular for free space laser communication. Conventional underwater communication is done acoustically with very slow data rates, short reach, and vulnurable for interception. AlGaInN blue-green laser diode technology allows the possibility of both airbourne links and underwater telecom that operate at very fast data rates $(\mathrm{GHz})$, long reach (100's of metres underwater) and can also be quantum encrypted.

The latest developments in AlGaInN laser diode technology are reviewed for defence and security applications. The AlGaInN material system allows for laser diodes to be fabricated over a very wide range of wavelengths from u.v., $\sim 380 \mathrm{~nm}$, to the visible $\sim 530 \mathrm{~nm}$, by tuning the indium content of the laser GaInN quantum well. Ridge waveguide laser diode structures are fabricated to achieve single mode operation with optical powers of $>100 \mathrm{~mW}$. Visible light communications at high frequency (up to $2.5 \mathrm{Gbit} / \mathrm{s}$ ) using a directly modulated $422 \mathrm{~nm}$ Galliumnitride $(\mathrm{GaN})$ blue laser diode is reported in free-space and underwater.
\end{abstract}

PACS: 42.55.Px; 42.60.By

Keywords: GaN laser, GaN array, free-space communication,

Atmospheric Propagation XIII, edited by Linda M. Thomas,

Earl J. Spillar, Proc. of SPIE Vol. 9833, 983309 - (c) 2016 SPIE

CCC code: 0277-786X/16/\$18 - doi: 10.1117/12.2208330

Proc. of SPIE Vol. 9833 983309-1 


\section{Results}

The lack of a suitable low defectivity and uniform GaN substrate has been one of the limiting factors for GaN laser diode technology. Recently, single crystal growth of large area, very low dislocation density and uniform GaN substrates are grown using a combination of high temperature and high pressure has been realised, enabling a range of AlGaInN laser technology to be developed ${ }^{1,2}$.

A typical AlGaInN laser diode epitaxy structure grown by MOCVD consists of; i) 0.8 $\mu \mathrm{m} \mathrm{Al}_{0.08} \mathrm{Ga}_{0.92} \mathrm{~N}$ lower cladding layer, ii) $50 \mathrm{~nm} \mathrm{GaN}$ lower waveguide layer, iii) $50 \mathrm{~nm}$ $\mathrm{In}_{0.02} \mathrm{Ga}_{0.98} \mathrm{~N}$ injection layer, iv) $\operatorname{In}_{\mathrm{x}} \mathrm{Ga}_{1-\mathrm{x}} \mathrm{N} / \mathrm{In}_{0.02} \mathrm{Ga}_{0.98} \mathrm{~N}$ quantum wells $\mathrm{x} 3(3.5 / 9 \AA)$ - the indium composition $\mathrm{x}(\mathrm{x}=0.05-0.2)$ and well thickness can be varied to change the emission wavelength, v) $20 \mathrm{~nm} \mathrm{Al}$. $_{0.2} \mathrm{Ga}_{0.8} \mathrm{~N}$ Electron Blocking Layer, vi) $80 \mathrm{~nm} \mathrm{GaN}$ waveguide and vii) $350 \mathrm{~nm}$ $\mathrm{Al}_{0.08} \mathrm{Ga}_{0.92} \mathrm{~N}$ upper cladding. All of the data presented in this paper are for AlGaInN laser diodes grown on the c-plane of the Wurtzite crystal.

AlGaInN epitaxy structures are processed into ridge waveguide LD's, with a typical mesa etch depth of $420 \mathrm{~nm}$, cavity length of $700 \mu \mathrm{m}$ and a stripe width varying from 3 to $10 \mu \mathrm{m}$. After cleavage, the LD's are $\mathrm{HR}$ coated $\left(5 \mathrm{x} \quad \mathrm{ZrO}_{2} / \mathrm{SiO}_{2}\right.$ quarter-wavelength layers) with $95 \%$ reflectivity and AR coated with $10 \%$ reflectivity. Devices are mounted p-side up on in TO5.6mm or TO9mm packages.

The LIV and the beam profile characteristics for a $2 \mu \mathrm{m}$ ridge waveguide LD structure packaged in a TO5.6mm package are shown in figure 1a). The device has a threshold current of $\sim 65 \mathrm{~mA}$, with a threshold voltage of $\sim 5 \mathrm{~V}$, a lasing wavelength of $410 \mathrm{~nm}$, and a characteristic temperature $T_{0}$ of $\sim 120 \mathrm{~K}$. A single transverse mode optical beam profile is observed in both the slow and fast axis with this device (see fig. $1 \mathrm{~b}$ ).
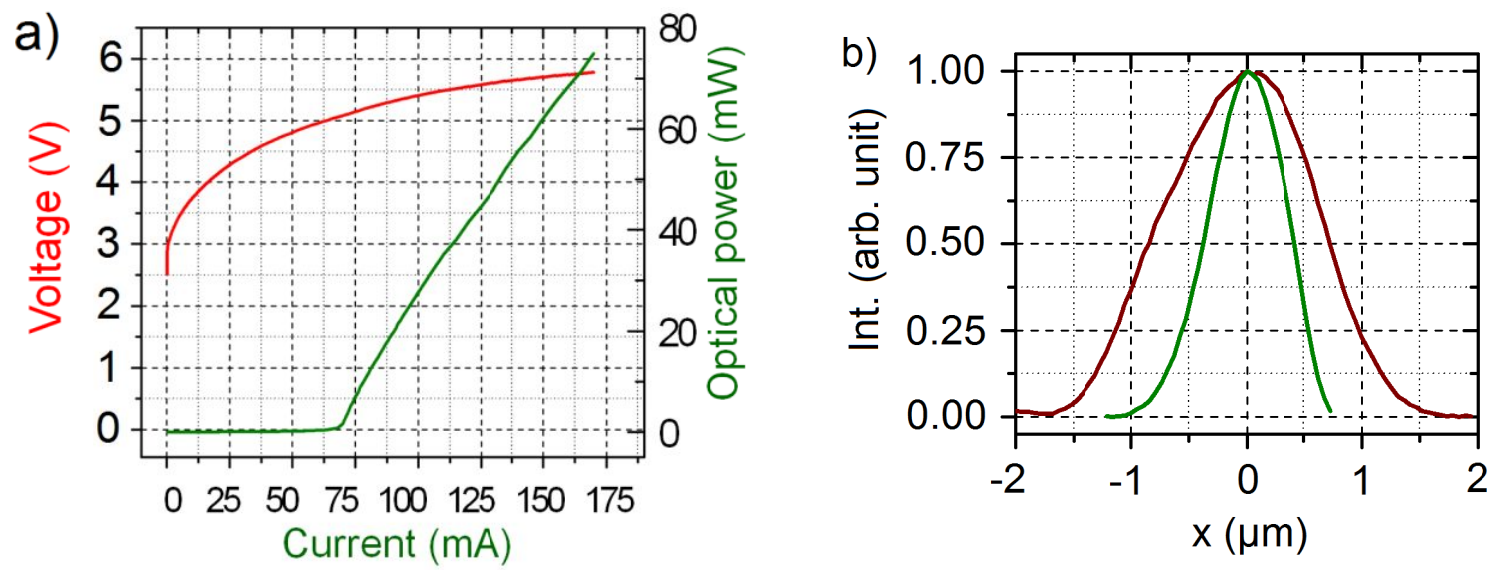

Fig.1 AlGaInN 410nm laser diode characteristics, a) LIV , b) Near-Field (slow axis - red line, fast axis - green line).

High resolution spectral measurements of the AlGaInN LD's reveal fine mode structure with a characteristic dominant single longitudinal mode more reminiscent of a DFB type of laser device with etched grating, providing optical feedback for mode selection, rather than a more 
standard 'mode comb' Fabry-Perot device with no etch grating. The single mode characteristics of a $422 \mathrm{~nm} \mathrm{GaN}$ laser diode is measured at $24 \mathrm{~mW}$ operation, a dominant single longitudinal mode at $421.6 \mathrm{~nm}$, with multiple small side modes is observed (see left hand side of figure 2). Similar single longitudinal mode characteristics has also been observed in the spectral output of other AlGaInN laser diodes and was explained by surface roughness inadvertently introduced during growth ${ }^{3}$ and that the single mode is stabalised by longitudinal mode competition caused by optical gain saturation ${ }^{4}$. Similarly we observe a surface topology of the order of $\sim 10 \mathrm{~nm}$ in height and a periodicity of $100 \mathrm{~nm}^{5}$, eventhough the epitaxy growth is done on very low defectivity $\left(<5 \times 10^{4} \mathrm{~cm}^{-2}\right)$ GaN substrates with a flatness of $<0.1 \mathrm{~nm}^{6}$, the surface topology features appear inadvertantly in the last epitaxy layer of growth.
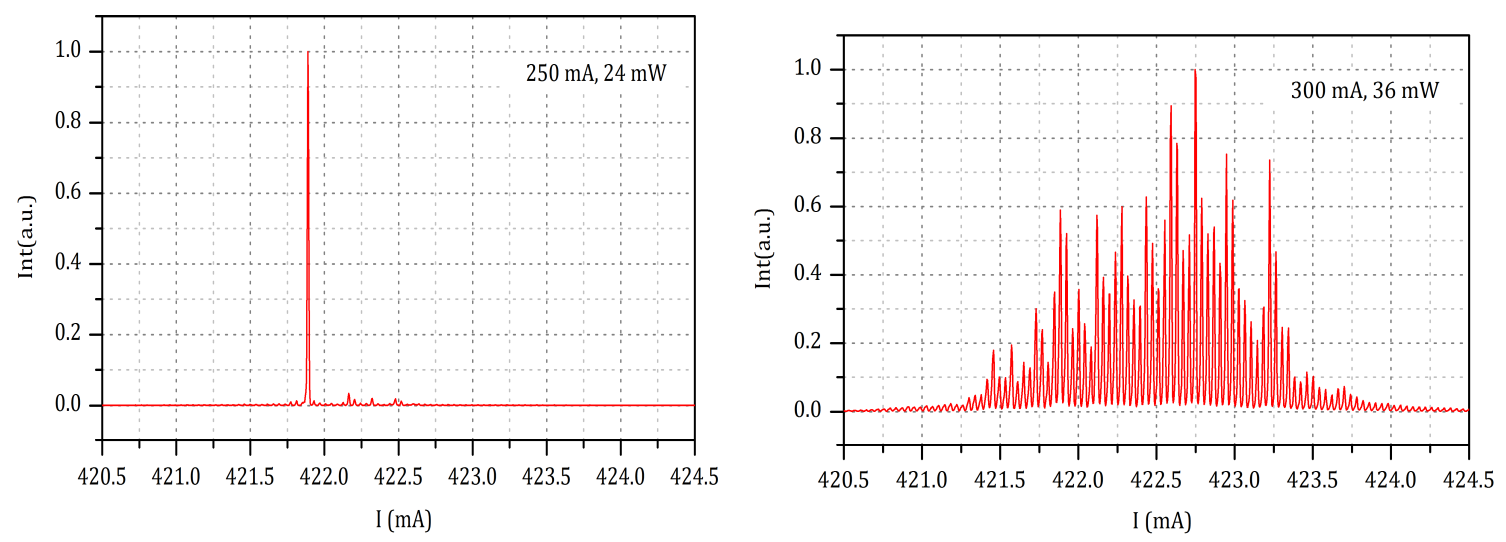

Fig 2 The evolving spectra of a 422nm GaN LD's vs increasing drive current $\mathrm{mA}$ /optical power $\mathrm{mW}(\mathrm{cw})$ at $20^{\circ} \mathrm{C}$

The dominant single mode characteristic is observe in all our AlGaInN LD devices at moderate optical powers up to $\sim 25 \mathrm{~mW}$. At a higher optical power $(36 \mathrm{~mW})$, the single longitudinal mode jumps to a spectrally wide $(\sim 1-2 \mathrm{~nm})$ mode comb as is more typical of a Fabry-Perot LD device (see right hand side of figure.2).

The narrow linewidths of the GaN laser diode shows the potential of the technology for telecommunication applications (as well as other applications that require very narrow linewidths, such as atomic clocks). In addition, the wavelength tunability of the AlGaInN system allows nitride laser diodes to be tuned to specific telecom applications, such as free-space, high speed data transmission at a Fraunhofer line, e.g., 422nm, for a low solar background to underwater. Or for more borad-band telecom applications such as wavelength multiplexing in plastic optical fibre.

Free space data transmission measurements were carried out using GaN blue laser diodes. Eye diagrams, measured using an Agilent 86105B digital sampling oscilloscope (DCA), are shown in figure 3. High frequency data transmission at $1.1 \mathrm{Gbit} / \mathrm{s}$ was measured for a laser drive current of $115 \mathrm{~mA}$ and $2.5 \mathrm{Gbit} / \mathrm{s}$ for $120 \mathrm{~mA}$, at which the best $\mathrm{Q}$ factor margins are achieved ${ }^{7}$. 

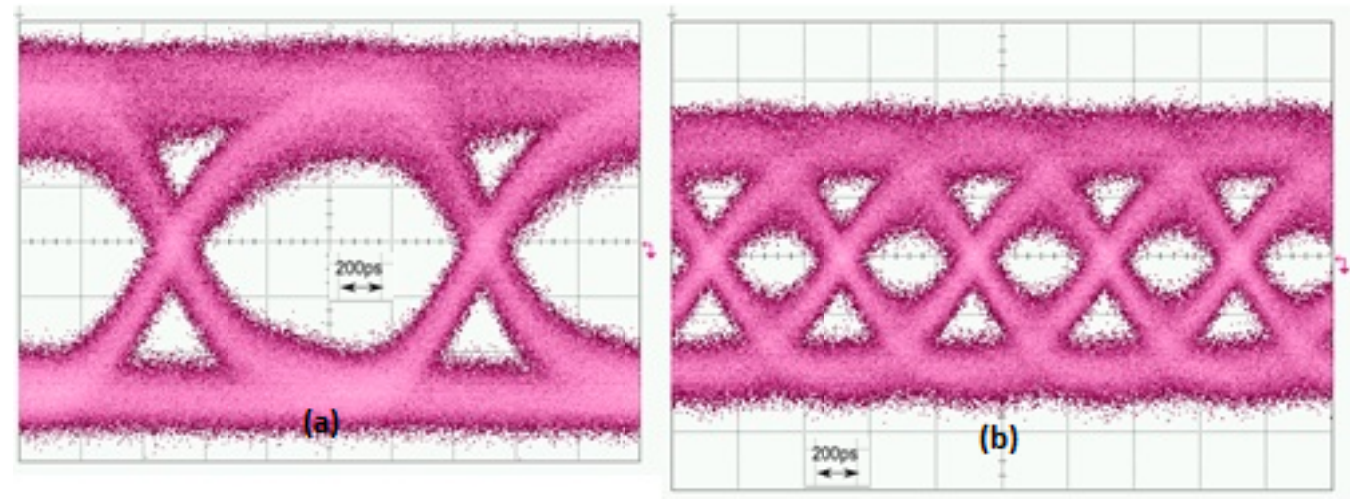

Figure 3. Eye diagrams at (a) $1 \mathrm{Gbit} / \mathrm{s}$ and (b) $2.5 \mathrm{Gbit} / \mathrm{s}$ at photo-receiver output.

To test the suitability of GaN laser diode technology for under water communications, a GaN laser optical tracking system was constructed and submerged in a water tank and its performance was determined as the water conditions were varied by introducing Maalox which mimics the volume scattering of seawater particles and is commonly used in underwater light-scattering experiments. Several GaN laser diodes were tested over a short underwater path length of 1 metre with their centre wavelength in the range of $421 \mathrm{~nm}$ to $425 \mathrm{~nm}$ (see figure 4 below). These wavelengths are in the range corresponding to lowest attenuation for optical wavelengths in waters classed as 'oceanic clear', whereas with increasing turbidity the lowest attenuation shifts to longer wavelengths.

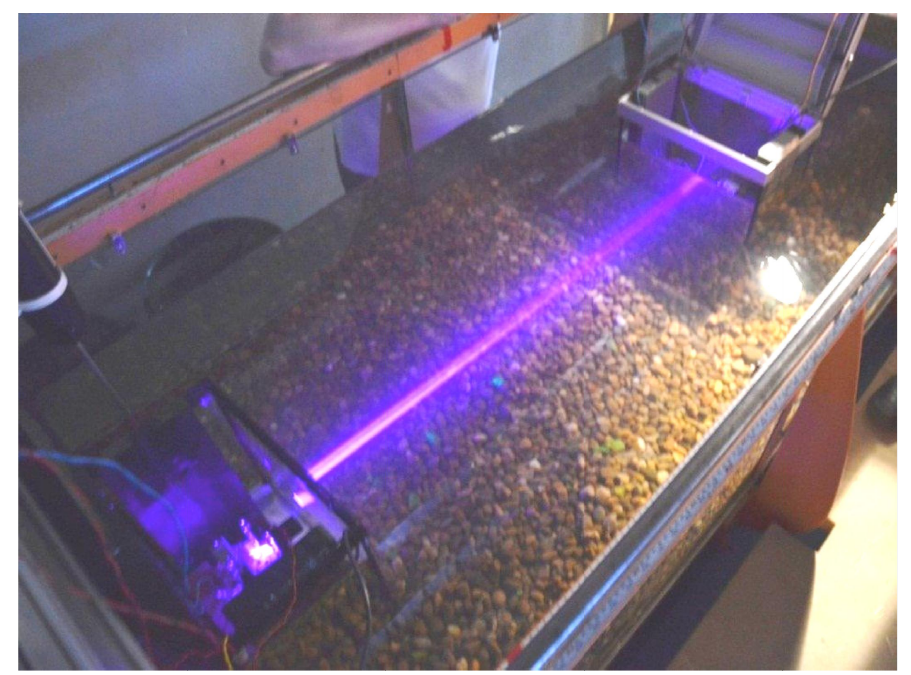

Figure 4.: Collimated laser fired underwater from node to node in harbour type water, over a $1 \mathrm{~m}$ distance. 
High-frequency data transmission under water at similar Gbit/s rates has also been measured using a $422 \mathrm{~nm}$ GaN laser diode (see figure 5) demonstrating the suitability of $\mathrm{GaN}$ system technology for underwater sensing and communications ${ }^{8,9}$.
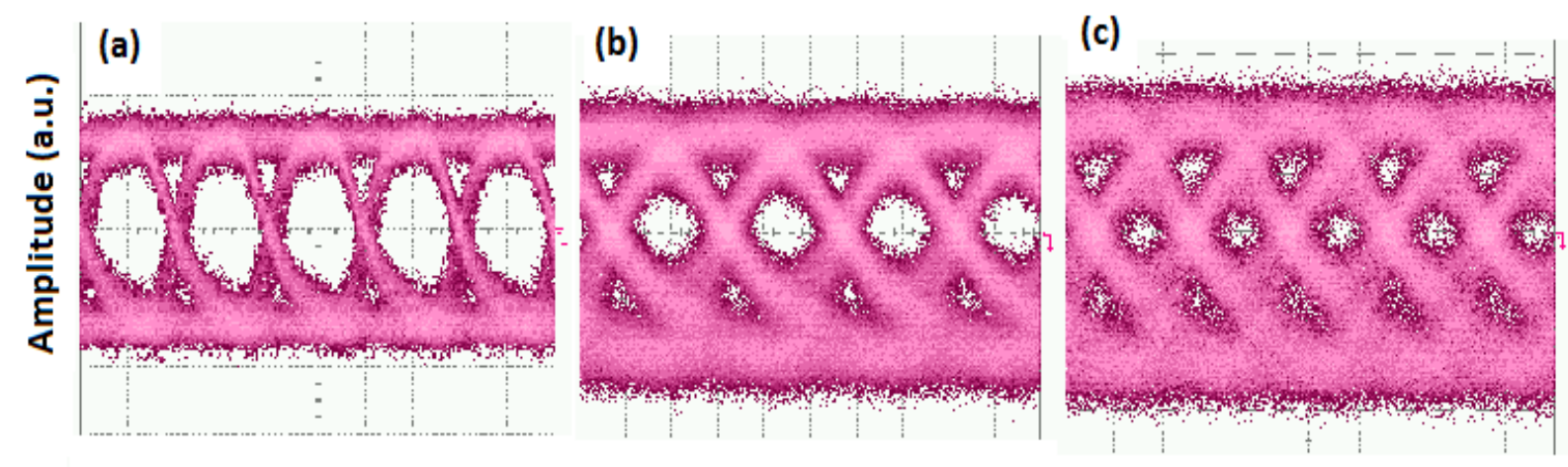

Figure 5: Eye diagrams showing data transmission for a signal transmitted through water at (a) $1 \mathrm{Gbit} / \mathrm{s}$ at $125 \mathrm{~mA}$ drive current, (b) $2 \mathrm{Gbit} / \mathrm{s}$ at $132 \mathrm{~mA}$ and (c) $2.488 \mathrm{Gbit} / \mathrm{s}$ at $132 \mathrm{~mA}$.

\section{CONCLUSIONS}

$\mathrm{GaN}$ laser technology has the potential for a compact, very high data rate $(\mathrm{GHz})$ source for novel telecommunication applications such as underwater optical communications. We measure blue light (free-space and underwater) communications at high frequency (up to $\sim 2.5 \mathrm{Gbit} / \mathrm{s}$ ) using a directly modulated $422 \mathrm{~nm}$ Gallium-nitride $(\mathrm{GaN})$ blue laser diodes.

Acknowledgements:

This research has been supported by the European Union with grant E!9776 and the National Centre for Research and Development within the project E!9776/NCBiR/2015.

References:

1) R. Dwilinski, R. Doradzinski, J. Garczynski, L. P. Sierzputowski, A. Puchalski, Y. Kanbara, K. Yagi, H. Minakuchi, and H. Hayashi: J. Cryst. Growth 310 (2008) 3911.

2) M. Bockowski, I. Grzegory, B. Łucznik, T. Sochacki, G. Nowak, B. Sadovyi, P. Strak, G. Kamler, E. Litwin-Staszewska, S. Porowski, Journal of Crystal Growth, 350, 5 (2012).

3) T.Meyer, H.Braun, U.Schwarz, S.Tautz, M.Schillgalies, S.Lutgen and U.Strauss, p.6833, Vol.16, No.10, Optics Express (2008).

4) Thomas Weig, Thomas Hager, Georg Brüderl, Uwe Strauss, and Ulrich T. Schwarz, Optics Express 22, 27489 (2014) 
5) S.P. Najda, P. Perlin, T. Suski, L. Marona, M. Bockowski, M. Leszczynski, A. Kafar, S. Stanczyk, P. Wisniewski, R. Czemecki, R. Kucharski and G. Targowski

Proc. SPIE Vol. 8733, 873302-1, edited by Mark Dubinskii \& Stephen G.Post, ISBN 9780-8194-9524-2

6) M. Bockowski, I. Grzegory, B. Lucznik, T. Sochacki, G. Nowak, B. Sadovyi, P. Strak, G. Kamler, E. Litwin-Staszewska, S. Porowski, Journal of Crystal Growth 07/2012; 350(1):5-10.

7) Scott Watson, Mingming Tan, Stephen P. Najda, Piotr Perlin, Mike Leszczynski, Grzegorz Targowski, Szymon Grzanka and A.E.Kelly

Optics Letters Vol.38, No.9. p3792 (2013).

8) Malcolm A. Watson; Paul M Blanchard; Chris Stace; Priya K. Bhogul; Henry J. White; Anthony E. Kelly; Scott Watson; Manousos Valyrakis; Stephen P. Najda; Lucja Marona; Piotr Perlin.

Proc. SPIE 9248, Unmanned/Unattended Sensors and Sensor Networks X, 92480T (17 October 2014); doi: 10.1117/12.2073675

9) Stephen P. Najda, Piotr Perlin, Tadek Suski, Lucja Marona, Mike Boćkowski, Mike Leszczyński, Przemek Wisniewski, Robert Czernecki, Robert Kucharski, Grzegorz Targowski, Scott Watson, and Antony E. Kelly.

Proc. SPIE 9254, Emerging Technologies in Security and Defence II; and QuantumPhysics-based Information Security III, 92540Z (31 October 2014); doi: $10.1117 / 12.2072172$. 